\title{
Tablet with Sensor Dosage Form
}

National Cancer Institute

\section{Source}

National Cancer Institute. Tablet with Sensor Dosage Form. NCI Thesaurus. Code C147579.

A solid dosage form containing medicinal substances, with or without suitable diluents, plus an ingestible sensor that communicates with medical devices that are usually located outside of the body. 